\title{
Geogenic and agricultural controls on the geochemical composition of European agricultural soils
}

\author{
Gerben Mol (1), Remon Saaltink (2), Jasper Griffioen (3), and Manfred Birke (4) \\ (1) Alterra, Wageningen University \& Research Centre, Wageningen Campus, P.O. Box 47, 6700 AAWageningen, The \\ Netherlands (gerben.mol@wur.nl), (2) Department of Environmental Sciences, Copernicus Institute of Sustainable \\ Development, Utrecht University, 3508 TC Utrecht, The Netherlands, (3) Deltares and TNO Geological Survey of the \\ Netherlands, Princetonlaan 6, 3584 CB Utrecht, Netherlands, (4) Federal Institute for Geosciences and Natural Resources \\ (BGR), Branch office Berlin, Wilhelmstr. 25-30, 13593 Berlin, Germany
}

Purpose: Concern about the environmental impact of agriculture caused by intensification is growing as large amounts of nutrients and contaminants are introduced into the environment. The aim of this paper is to identify the geogenic and agricultural controls on the elemental composition of European, grazing and agricultural soils.

Materials and methods: Robust factor analysis was applied to data series for Al,B, Ca, Cd, Co, Cu, Fe, K, Mg, Mn, $\mathrm{Na}, \mathrm{Ni}, \mathrm{P}, \mathrm{S}, \mathrm{Se}, \mathrm{Sr}, \mathrm{U}, \mathrm{Zn}$ (ICP-MS) and $\mathrm{SiO}_{2}, \mathrm{~K}_{2} \mathrm{O}, \mathrm{Na}_{2} \mathrm{O}, \mathrm{Fe}_{2} \mathrm{O}_{3}, \mathrm{Al}_{2} \mathrm{O}_{3}$ (XRF) based on the European GEMAS dataset. In addition, the following general soil properties were included: clay content, $\mathrm{pH}$, chemical index of alteration (CIA), loss on ignition (LOI), cation exchange capacity (CEC), total organic carbon (TOC) and total carbon and total sulfur. Furthermore, this dataset was coupled to a dataset containing information of historic $\mathrm{P}_{2} \mathrm{O}_{5}$ fertilization across Europe. Also, a mass balance was carried out for $\mathrm{Cd}, \mathrm{Cu}$ and $\mathrm{Zn}$ to determine if concentrations of these elements found in the soils have their origin in historic $\mathrm{P}_{2} \mathrm{O}_{5}$ fertilization.

Results and discussion: Seven geogenic factors and one agricultural factor were found of which four prominent ones (all geogenic): chemical weathering, reactive iron-aluminum oxide minerals, clay minerals and carbonate minerals. Results for grazing and agricultural soils were near identical, which further proofs the prominence of geogenic controls on the total elemental composition. When the cumulative amount of $\mathrm{P}_{2} \mathrm{O}_{5}$ fertilization was considered, no extra agriculture-related factors became visible. The mass balance confirms these observations.

Conclusion: Overall, the geological controls are more important for the total soil chemistry in agricultural and grazing land soils than the anthropogenic controls. 